\title{
Educação Física escolar e as questões de gênero: a prática pedagógica em foco
}

\section{RESUMO}

$\mathrm{O}$ presente artigo refere-se à uma pesquisa descritiva de caráter quanti-qualitativo que envolveu 15 professores/as de educação física da Rede de Ensino da cidade de Dourados/MS, com o objetivo de investigar como a intervenção docente tem trabalhado as questões de gênero e sexualidade na Educação física escolar, procurando vislumbrar possibilidades de atividades corporais e esportivas numa dimensão de igualdade e valorização da diversidade. Para a coleta de dados utilizou-se questionário online (com questões abertas e fechadas) pela plataforma Google Forms. Entre os achados do estudo, constatou-se que a grande maioria dos professores/as nunca trabalharam com discussões de gênero e sexualidade e demonstram dificuldades em relação a problematizar a temática, mesmo que isso acarrete a reprodução de uma educação física de cunho sexista, binário e biologizante.

PALAVRAS-CHAVE: Educação física escolar; Gênero e sexualidade; Práticas pedagógicas
Luiz Henrique Poloni

Graduado em Educação Física

Universidade Federal da Grande

Dourados, Faculdade de Educação,

Dourados, Brasil

luizhenriquepoloni@gmail.com Ohttps://orcid.org/0000-0002-5849-7078

Cássia Cristina Furlan

Doutora em Educação

Universidade Federal da Grande

Dourados, Faculdade de Educação,

Dourados, Brasil

cassiacfurlan@gmail.com

Dhttps://orcid.org/0000-0002-8175-9320 


\title{
Physical Education, sports and gender relations: the pedagogical practice in focus
}

\begin{abstract}
This article refers to a quantitative and qualitative descriptive research involving 15 Physical Education teachers from the Teaching Network in the city of Dourados / MS, with the objective of investigating how the teaching intervention to the content of gender and sexuality has been Physical Education and analyze the pedagogical practice of teachers in a dimension of equality and valuing diversity. For this, as data collection, an online questionnaire was used (with open and closed questions) through the Google Forms platform. Among the findings of the study, it was found that the vast majority of teachers never work with the content of gender and sexuality. It was not possible to identify the barriers that led to this. Also, it was found that the teachers prioritized equality in the class administrations. It could be concluded that from this content, there is still room for improvement since Physical Education can contribute much more to the students' "social" formation.
\end{abstract}

KEYWORDS: School physical education; Gender and sexuality; Pedagogical practices

\section{Educación física, deporte y relaciones de género: la práctica pedagógica en foco}

\section{RESUMEN}

Este artículo se refiere a una investigación descriptiva cuantitativa y cualitativa que involucró a 15 profesores de Educación Física de la Red de Enseñanza de la ciudad de Dourados / MS, con el objetivo de indagar cómo se ha realizado la intervención docente en los contenidos de género y sexualidad. Educación Física y analizar la práctica pedagógica de los docentes en una dimensión de igualdad y valoración de la diversidad. Para ello, como recolección de datos, se utilizó un cuestionario en línea (con preguntas abiertas y cerradas) a través de la plataforma Google Forms. Entre los hallazgos del estudio, se encontró que la gran mayoría de profesores nunca trabaja con el contenido de género y sexualidad. No fue posible identificar las barreras que llevaron a esto. Asimismo, se encontró que los docentes priorizaron la igualdad en la administración de clases. Se puede concluir que a partir de este contenido aún hay margen de mejora, ya que la Educación Física puede aportar mucho más a la formación "social" de los estudiantes.

PALABRAS-CLAVE: Educación física escolar; Género y sexualidad; Prácticas pedagógicas 


\section{INTRODUÇÃO}

Uma das principais preocupações da educação, no contexto geral, tem sido a falta de inclusão no ambiente escolar (SANTOS, 2009). Essa problemática também tem sido verificada nas aulas de educação física, implicando significantemente para a redução da participação dos/as alunos/as e na diminuição da adesão das pessoas ao exercício físico (PEREIRA; FERNANDES, 2009).

Esta realidade pode ser relacionada aos diferentes focos da educação física ao longo da história. No sentido de separação de gêneros, percebemos que em diferentes momentos históricos da educação física, a exemplo daquilo que alguns autores irão denominar de Educação Física Higienista e Militarista (DARIDO; RANGEL, 2005) havia uma gama de atividades que comprometiam a igualdade de gênero nas aulas. Algumas justificativas se pautavam em afirmações de que as mulheres eram frágeis e os exercícios traziam riscos para a fertilidade. Esses discursos machistas acabaram por sedimentar "raízes" na área de educação física e que legitimaram, por muito tempo, a separação das práticas entre meninos e meninas (GHIRALDELLI, 1998). Diante desta realidade, a Educação Física escolar contribuiu por masculinizar o desporto e feminizar as atividades rítmico-expressivas, socializando corpos masculinos e femininos, porém, separando-os (SARAIVA, 2002).

Atualmente, ainda encontramos resquícios dessas restrições na participação efetiva das meninas nas aulas mistas no contexto escolar e/ou na diferenciação de atividades voltadas à meninos e meninas, carregadas de estereótipos. Pesquisas como as de Jacó (2012) apontaram que o desempenho e as habilidades são fatores que influenciam na discriminação das meninas durante as aulas. Cabe salientar que tanto desempenho quanto à aquisição de habilidades são aspectos que são adquiridos com a prática frequente e motivadora, fatos que podem corroborar para que meninas, por uma questão histórica, possam ser desfavorecidas.

Logo, enfatiza-se que as questões de gênero precisam fazer parte da formação profissional, buscando-se alternativas pedagógicas para que as aulas de educação física possam trazer mudanças nas relações de poder constituídas entre os gêneros na prática dos desportos e das atividades físicas durante as aulas atuando diretamente na desconstrução dos binarismos sobre os corpos masculinos e femininos (JESUS; DEVIDE, 2006).

Em detrimento a esta problemática, a Educação Física é umas das áreas que mais pode contribuir para a desconstrução desses "estereótipos" de separação e produção de noções sexistas na sociedade, visto trabalhar diretamente com o corpo em movimento. Mas, para que o resultado aconteça é necessário que haja intervenção docente. Nesse sentido, essa pesquisa busca 
problematizar alguns aspectos relacionados à atuação docente, no que tange às questões de gênero e sexualidade. O objetivo deste estudo foi investigar como a intervenção docente tem trabalhado as questões de gênero e sexualidade na educação física escolar, procurando vislumbrar possibilidades de atividades corporais e esportivas numa dimensão de igualdade e valorização da diversidade. É uma pesquisa descritiva, de caráter quanti-qualitativo direcionada à 15 professores/as da Rede Estadual e Municipal de Dourados-MS. A metodologia utilizada foi a aplicação de questionário online, via Google Forms, enviado aos/às professores/as da Rede de Ensino, com perguntas abertas e fechadas sobre o assunto em pauta.

Os/as professores/as foram convidados/as a participarem da pesquisa via redes de contatos estabelecidos inicialmente entre a universidade e a pessoa responsável à época pelo Núcleo de Educação Física da Secretaria Municipal de Educação. Em momentos anteriores ao desenvolvimento desta pesquisa, foram ofertadas formações continuadas para os/as docentes, que foram consultados/as quanto à sua disponibilidade em participarem de pesquisas futuras. Assim, os primeiros contatos foram realizados presencialmente, quando ainda não estávamos afetados pela pandemia da COVID-19. No entanto, o desenvolvimento da pesquisa e a aplicação do questionário ${ }^{1}$ foram realizados em período pandêmico. Ao realizarmos o contato para o convite à pesquisa, solicitamos a colaboração do Núcleo de Educação Física na divulgação da pesquisa para os/as professores/as de educação física da rede de ensino. Cabe ressaltar que os/as docentes foram convidados por meio de grupos em meios digitais direcionados às formações e comunicações entre docentes da rede municipal. Assim, o questionário atingiu prioritariamente professores/as da rede municipal, mas que em alguns casos também atuam/atuavam na rede estadual de educação.

O questionário foi estruturado inicialmente a partir de uma apresentação dos objetivos da pesquisa e dos/as pesquisadores/as. Em seguida, contou com 11 questões fechadas, visando a caracterização do grupo participante (gênero, idade, tempo de atuação, religião, tempo de formação, jornada de trabalho, dentre outras). Posteriormente, 15 questões (mescladas entre abertas e fechadas) com enfoque específico para a prática pedagógica e as questões de gênero.

\section{GÊNERO, SEXUALIDADE E EDUCAÇÃO FÍSICA}

Historicamente temos vislumbrado uma série de mudanças que tem provocado o questionamento de muitos valores e padrões de comportamento. As reivindicações dos movimentos

\footnotetext{
${ }^{1}$ A escolha por este instrumento de pesquisa se deu pela dificuldade de acesso aos/as docentes em período de pandemia da COVID-19. A princípio, pretendíamos desenvolver a pesquisa presencialmente, via entrevistas, a partir dos contatos já estabelecidos em formações continuadas. Mas, dadas as condições sanitárias, houve alteração da metodologia de coleta de dados, para favorecer as medidas de biossegurança empregadas pelas autoridades sanitárias.
} 
feministas, o surgimento da pílula anticoncepcional e suas consequências para a autonomia das mulheres, a liberação sexual, os avanços da medicina e o processo de laicização do Estado resultaram em profundas transformações sociais e culturais. $\mathrm{O}$ conceito de gênero tem origem nesse contexto de luta do movimento feminista para conquista de direitos políticos e sociais das mulheres (MONTEIRO; SOARES, 2019).

Louro (1997, p.22-23), ao delinear as significações do termo "gênero", amplamente disseminado a partir da década de 1970 e 1980 pelos movimentos feministas, afirma que o mesmo se refere ao "[...] modo como as características sociais são compreendidas e representadas. Na medida em que o conceito afirma o caráter social do feminino e do masculino obriga a [...] levar em consideração as distintas sociedades e os distintos momentos históricos".

No contexto atual, gênero passa a significar muito mais do que representações baseadas numa distinção biológica, representando construções culturais e sociais que permitem a percepção de identidades, problematizando binarismos alicerçados no sistema sexo-gênero e no enquadramento à uma linearidade e decorrência sexo $\rightarrow$ gênero $\rightarrow$ desejo, alicerçada no conceito da heterossexualidade compulsória (BUTLER, 2003).

Sobre a sexualidade, Foucault (1993) afirma que ela é um "dispositivo histórico", é uma invenção social, constituída, historicamente, a partir de diversos discursos sobre o sexo: discursos "reguladores", que normatizam, fixam saberes, produzem e reproduzem "verdades".

Louro (2000), descreve em seu livro que há um senso comum que acredita que a sexualidade seria algo "dado" pela natureza, sendo inerente ao ser humano. Tal concepção se fundamenta na suposição de que nossos corpos, universalmente, vivem da mesma forma. Contudo, ressalta-se que a sexualidade envolve rituais, linguagens, fantasias, representações, símbolos, convenções. Engloba fatores culturais e históricos. Nesse sentido, a perspectiva é de que não haja nada exclusivamente "natural", a começar pela própria concepção de corpo, ou mesmo de natureza. Através de processos culturais e históricos, pode-se definir o que é - ou não - natural; Há produção e transformação da natureza e da biologia e, as tornamos históricas. Os corpos ganham sentido social. A compreensão do significado dos gêneros - feminino, masculino, ou mesmo fluído - é fruto, então, de um contexto cultural e, portanto, carrega as marcas dessa cultura.

Nesse contexto, é fundamental compreendermos que tanto gênero quanto sexualidade, para além de construções meramente biológicas e binárias, presentificam-se em diferentes contextos e culturas e constituem a vida das pessoas, agregam valores e significados, desenvolvem-se de diferentes modos e não são características fixas e essencialistas. Isso não quer dizer que a materialidade corpórea (biológica, fisiológica) seja negada, mas que as significações que se fazem 
sobre esse corpo biológico constituem-se pela linguagem e pelo discurso e interpretam-se diferentemente, de acordo com a cultura e o contexto vivenciados.

Assim, essas questões precisam ser debatidas em diferentes espaços e, inclusive na Educação Física. Se por um lado, discutir gênero e sexualidade tem nos permitido transpor diversas barreiras, por outro tem provocado ondas conservadoras em prol da defesa de alguns pressupostos excludentes e normatizadores.

Falar de gênero e sexualidade na educação física é olhar para o caminho histórico que constituiu a área. A educação física ao longo dos anos passou por diversas transformações que constituíram a sua identidade (e/ou, para muitos/as autores/as, a sua falta de identidade).

Aportes históricos vão explicitar de que modo o aparato legal e as concepções de corpos em meados de 1930 inferiorizavam as mulheres firmando a ideia de que as mulheres eram mais frágeis, delicadas e fracas em comparação aos homens na educação física escolar brasileira. O decreto/Lei 3.199, publicado em abril de 1941, instituiu no artigo 54 que "às mulheres não se permitirá a prática de desportos incompatíveis com as condições da sua natureza" (BRASIL, 1941). Naquele contexto, as mulheres não tinham plena liberdade para inserção na vida pública e participação em práticas corporais.

Próximo aos anos 1970, o Decreto-Lei n. 3.199 é revogado, momento em que o Brasil vivenciava a ditadura militar (1964-1985). Durante esse período, houve acirrada intervenção governamental nas concepções de educação física voltadas à uma dimensão esportiva, empregando o esporte como um instrumento para a manutenção do status quo da política que se constituía no período e, portanto, como forma de propagação e legitimação de suas ações, propaganda nacional e também de alienação da população dos eventos políticos que aconteciam (JACO, 2012).

Após diversas experiências, com mudanças no contexto social e político, a educação física também começa a se repensar e provocar cisões em relação à algumas lógicas segregatórias, militaristas e/ou mesmo extremamente técnicas, que continuavam a valorizar excessivamente habilidades e desempenho, num contexto de exclusão e segregação de meninos e meninas à determinadas práticas.

A área começa a se reconstruir, com uma perspectiva preocupada com o ensino de conteúdos de forma pedagógica, coerente, com o foco em aulas inclusivas, considerando aspectos sociais, culturais, afetivos e físicos. As reflexões e os questionamentos que surgiram entre 1980 e 1990 na área contribuíram para novas concepções de corpo e de educação física, fundamentadas por outas áreas de conhecimentos (biológica, ciências humanas, psicologia, sociologia, história e antropologia), mesmo que muitas dessas concepções e abordagens ainda se consolidassem a partir 
de visões predominantemente separadas por sexo, com enfoques para aptidões físicas e destrezas técnicas (SOARES, 1996).

Por meio dos programas de pós-graduação na área da educação, a literatura da área, a partir da década de 1980, começa a aprofundar-se nas questões de gênero e sexualidade. Assim, foram surgindo diversos questionamentos acerca de gênero e sexualidade na educação física, como por exemplo: condições de aprendizagem, concepções de masculinidade e feminilidade, tipos de práticas corporais ideais para homens e mulheres, respeito nas aulas e igualdade de oportunidades.

Nesse sentido, quando se fala em gênero e sexualidade na/para a educação física, estamos falando da constituição de corpos e experiências corporais extrapolando a noção de corpo como uma dimensão eminentemente biológica (GOELLNER, 2003).

Goellner (2003, p. 29) afirma: “Um corpo não é apenas um corpo. É também o seu entorno. Mais do que um conjunto de músculos, ossos, vísceras, reflexos e sensações, o corpo é também a roupa e os acessórios que o adornam, as intervenções que nele se operam”. Nesse contexto, para compreender como esses corpos se presentificam e atuam na sociedade, é preciso, como aponta Geertz (1989, p. 23), “[...] identificar e perceber como as pessoas são, como se relacionam, como agem e interagem, e mergulhar no significado das ações identificadas pelos indivíduos em suas sociedades, tornando relevante a cultura onde vivem".

Corsino e Auad (2012), na pesquisa intitulada 'Questões de gênero na Educação Física escolar: o professor diante das relações de gênero na Educação Física escolar', refletem sobre o processo de hierarquização de gênero nas aulas. Os/as autores/as elucidam que os estudos de gênero na área não são recentes e que vem provocando transformações, indicando, entretanto, que aulas mistas não bastam para proporcionarem igualdade nas práticas corporais e esportivas, propondo caminhos para pensar numa dimensão coeducativa, já apontada anteriormente por Saraiva (2002). Na pesquisa, de cunho aplicado, Corsino e Auad (2012) apontam para a importância de perceber as relações desiguais que ainda se estabelecem nas aulas, por toda uma construção histórica e social, enfatizando a necessidade de uma educação para as questões de gênero e sexualidade desde a formação inicial de professores/as, para potencializar um trabalho mais efetivo com essas questões.

Nesse processo histórico, vivenciamos diversos avanços e iniciativas pautadas pela desconstrução de binarismos de gênero nas práticas corporais e esportivas, erigindo uma educação física comprometida com a educação igualitária e crítica. No entanto, o processo histórico também possibilita compreender os desafios dessa reconstrução, visto que normas e valores sociais estão atrelados às noções de corpos e esse processo requer, sobretudo, a quebra de paradigmas que estão, inclusive, nos/as próprios/as docentes, que promovem intervenções no âmbito da educação física. 
Os/as professores/as de educação física precisam intervir para que seus/suas alunos/as tenham uma visão positiva, responsável e respeitosa acerca das questões de gênero e da sexualidade, isto devido à realidade e a proximidade entre professor/a e aluno/a no contexto escolar (SAYÃO, 1997). Assim, será que o/a professor/a de educação física está preparado para lidar com essas questões? Há a preocupação com a valorização de experiencias diversas nas aulas de educação física, visando a inclusão e participação de todos/as, independente de gênero, classe, raça, orientação sexual? Essas são questões que precisam perpassar uma reflexão mais aprofundada sobre o papel docente nas aulas de educação física.

\section{INTERVENÇÃO DOCENTE: Educação Física, Gênero e Sexualidade}

Inúmeras são as possibilidades para desenvolver temáticas relacionadas a gênero e sexualidade em sala de aula, no entanto, esse assunto ainda é tratado de forma limitada por se configurar, ainda hoje, como um tabu.

Em resposta a esta realidade, Abreu e Wandekoken (2005) afirmam que a educação física pode contribuir para a formação social das pessoas, a formação para a cidadania e para o respeito ao próximo. No entanto, ao adotar atitudes sexistas, a exemplo da divisão de uma turma em masculina e feminina, com práticas distintas, o/a professor/a responsável acaba descartando o principal objetivo da educação física que é promover a formação integral crítico-reflexiva e autônoma.

Nessa perspectiva, alguns estudos exploram alternativas que podem auxiliar na prática pedagógica, no sentido de inclusão de todos/as. Lovisi, Procópio e Mourão (2013, p.7) expõe a importância da adoção de uma abordagem metodológica adequada pelo/a docente. Os/as autores/as identificaram a sistematização e organização didático-pedagógica do conhecimento, como um meio de aproximar todos os/as alunos/as aos conteúdos e levá-los a praticarem. Relatam que inicialmente havia uma ambientação e contextualização acerca do conteúdo a ser abordado e sequencialmente a vivência, com atividades que mesclavam meninas e meninos, demonstrando que esse processo, já introjetado pelos/as alunos/as, acontecia 'naturalmente', sem diferenciações de gênero nas práticas corporais e esportivas (LOVISI; PROCÓPIO; MOURÃO, 2013).

A educação física representa uma ampla área de conhecimento, sendo o/a professor/a o/a mediador/a desse conhecimento. Para Lovisi, Procópio e Mourão (2013) a criatividade em relação a diversificação dos conteúdos e temas das aulas é fundamental à prática docente, favorecendo uma prática pedagógica crítica e inclusiva. 
Salienta-se a importância de se refletir sobre a necessidade de formação específica dos/as docentes para o trato com essas questões, visando uma prática pedagógica mais consciente, diversificada e que permita a todos e todas a participação efetiva, inclusiva e respeitosa. Sendo assim, como os/as professores/as de Dourados/MS tem compreendido e trabalhado com essas questões em suas aulas?

\section{RESULTADOS E DISCUSSÕES}

O quadro abaixo apresenta informações sobre o gênero, média de idade, média do tempo de atuação na educação física escolar, religião dos/as participantes da pesquisa e raça/etnia (15 participantes). Os dados da pesquisa foram analisados de forma descritiva e tabulados, de maneira a melhorar a visualização e complementar os resultados.

Quadro 1 - Informação amostral complementar da pesquisa.

\begin{tabular}{|c|c|c|c|c|}
\hline Gênero & $\begin{array}{c}\text { Média de } \\
\text { idade (anos) }\end{array}$ & $\begin{array}{l}\text { Média do tempo } \\
\text { de atuacão (anos) }\end{array}$ & Religião & Raça/etnia \\
\hline $\begin{array}{c}80 \% \text { mulheres }(\mathrm{N}=12) \\
20 \% \text { homens }(\mathrm{N}=3)\end{array}$ & 34,4 & 5,2 & $\begin{array}{c}60 \% \text { católicos }(\mathrm{N}=9) \\
20 \% \text { evangélicos }(\mathrm{N}=3) \\
13,3 \% \text { espírita }(\mathrm{N}=2) \\
6,7 \% \text { não tem religião }(\mathrm{N}=1)\end{array}$ & $\begin{array}{l}33,3 \% \text { brancos } \\
66,7 \% \text { pardos }\end{array}$ \\
\hline
\end{tabular}

Fonte: autores (2021).

Verifica-se que $80 \%$ das participantes desta pesquisa são mulheres e apenas $20 \%$ são homens. Ressalta-se, também, que a média de tempo de atuação na educação pode contribuir bastante para as vivências dos/as pesquisados/as como profissionais da área.

Falar sobre gênero e sexualidade na escola é um processo de desconstrução de barreiras, pois a discussão é rodeada de vários fatores que interferem na forma de pensar e agir dos/as jovens e dos/as docentes. Dos 15 questionários respondidos, 75\% (10 pessoas) nunca trabalharam com esse conteúdo nas aulas de educação física. A pergunta era: você já trabalhou com o tema gênero ou sexualidade nas aulas? se sim, o que te motivou? se não, o que considera como barreira? Dentre as respostas negativas, a maioria não cita motivos ou barreiras, nem sequer justificam a inexistência de abordagens com a temática. Algumas respostas explicitam essa questão:

Não exatamente. Já abordei gênero de maneira indireta fazendo questionamentos antes de trabalhar futebol e dança. Já sexualidade é um tema mais polêmico quando se trata de crianças (Márcia, 29²).

\footnotetext{
${ }^{2}$ Os nomes são fictícios, visando preservar o anonimato dos/as participantes.
} 
Sim, sempre abordei esses temas, para quebrar o paradigma de que as meninas são fracas, não sabem jogar e etc. Para aulas mistas esse trabalho é fundamental (Marcos, 28).

Sim. Não digo que algo motivou, pois está na grade curricular do município essa temática nas séries finais do ensino fundamental (José, 22).

Não. Atualmente trabalho bem mais aula prática (Paulo, 58).

Não. Só trabalho com crianças jardim (Isadora, 34).

Conforme Holanda et. al. (2010), existem barreiras para a efetivação de estratégias que garantam o desenvolvimento da temática de gênero e sexualidade, tais como: a falta de preparo e insegurança para lidar com este tema, que é cercado de tabus, tanto por parte dos familiares como dos/as educadores/as, com explicitado na fala de Marcia. Além disso, alguns/mas docentes não compreendem a transversalidade dessa discussão, como se o trabalho com as questões de gênero devesse ser vinculada a uma aula específica, uma temática de aula, sem perceberem que o gênero atravessa os corpos e as práticas a todo o momento, seja nas atividades diferenciadas, na reprodução de estereótipos de gênero, na divisão de meninos e meninas, desde a educação infantil (como ressaltado pela professora Isadora, quando justifica que não trabalha com essas questões). Quando o professor Paulo sinaliza que não debate essas questões por trabalhar com conteúdos eminentemente práticos, não compreende a importância de um trabalho que valorize a relação teoria e prática e, além disso, não se dá conta de que toda prática requer uma instrumentalização teórica, essencial a atuação consciente. Como afirma Paulo Freire (2011, p.39), “a prática docente crítica [...] envolve o movimento dinâmico, dialético, entre o fazer e o pensar sobre o fazer". E continua: "O saber que a prática docente espontânea ou quase espontânea, 'desarmada', indiscutivelmente produz é um saber ingênuo, um saber de experiência feito, a que falta a rigorosidade metódica que caracteriza a curiosidade epistemológica do sujeito".

No entanto, quando indagados sobre as estratégias para trabalharem gênero e sexualidade nas aulas, alguns relatos expõem:

Usei como premissa/exemplo o preconceito gerado em mulheres no futebol e homens na ginástica. A partir daí entrei no tema de gênero e sexualidade (José, 22). Sempre que trago este tema, mesmo que indiretamente, é quebrando tabus e comentários dos alunos. Tento falar sobre o tema de uma forma simples e tranquila para conscientizar a turma (Debora, 26).

Sempre trabalho a parte teórica trazendo a discussão em sala, e mostrando artigos e documentos (hoje temos bastante sobre esse tema, e até a copa do mundo de futebol feminino ao meu ver foi um avanço) para depois irmos para a prática (Marcos, 28).

Percebemos que alguns/mas professores/as instrumentalizam seus alunos/as acerca das temáticas em foco, reconhecendo a importância do trabalho para uma formação crítica acerca das práticas corporais e esportivas. 
Outra pergunta discorria acerca dos fatores que são importantes ao/à profissional na busca por uma aula atrativa para ambos os gêneros, igualdade e participação nas aulas ${ }^{3}$. Para 86,7\% dos/as professores/as, o planejamento das aulas é fundamental. Já para 80\%, conhecimento prévio, diversificação dos conteúdos e a quebra de tabus são importantes. 73,3\% assinalam que a aprendizagem de novos conteúdos, domínio sobre a turma e a junção e reflexão entre teoria, realidade e prática fazem diferença. No entanto, algo que nos chama atenção é que menor porcentagem de docentes considera relevante a formação continuada $(66,7 \%)$ e/ou mesmo a qualidade da formação docente, com apenas 33,3\%.

Dos resultados apresentados nessa questão, podemos observar o grau inferior atribuído à formação inicial e continuada. Esses dados representam incoerências em relação aos pontos mais relevantes anteriormente explicitados, uma vez que todos os demais representam elementos interligados à qualidade da formação, tanto inicial quanto continuada. Algumas pesquisas (VASCONSELOS; FERREIRA, 2020; FREITAS; SOUZA JUNIOR, 2020; LOVISI; PROCÓPIO; MOURÃO, 2013) apontam para a necessidade de pensarmos a formação e os saberes docentes atrelados ao debate de gênero.

Vasconselos e Ferreira (2020) indicam a importância da formação inicial. Em estudo realizado com licenciandos/as em educação física, os resultados da pesquisa sinalizam fragilidades conceituais e falta de articulação entre teoria e prática dessas temáticas ao longo dos cursos de formação, explicitadas pelos próprios/as acadêmicos/as. O artigo de Freitas e Souza Junior (2020) segue a mesma linha, contribuindo para elucidar a formação docente como um elemento essencial à capacidade de intervir sobre atitudes discriminatórias. Lovisi, Procópio e Mourão (2013) salientam que professores/as de Educação Física produzem saberes docentes diferenciados, ligados às suas histórias de vida, formação e experiência profissional. Além disso, suas práticas pedagógicas estão atravessadas por relações de gênero também diferenciadas, segundo as/os autoras/es, estando diretamente relacionadas aos modos de produção dos saberes docentes e, portanto, também às suas experiências na formação inicial e continuada.

Percebe-se que, para além de a maioria dos/as entrevistados/as não trabalharem com o conteúdo de gênero e sexualidade na Educação Física, há lacuna importante na formação sobre essas questões, perceptíveis nas justificativas e motivos para não inserirem essas temáticas na sua prática pedagógica.

Ainda mais preocupante, conforme a pergunta anterior, é o fato de a maioria dos/as entrevistados/as não considerarem importante uma boa formação. Para Maia et al. (2012) é

\footnotetext{
${ }^{3}$ Nesta questão, os/as participantes poderiam assinalar mais de uma alternativa.
} 
essencial a formação continuada dos/as educadores/as no campo da sexualidade, com o intuito de se organizarem de modo apropriado e com respaldo teórico para assumirem a tarefa educativa no ambiente escolar. Muitos/as educadores/as possuem dificuldades em orientar seus/as alunos/as por razões pessoais: falta de informações específica de gênero e sexualidade ou até mesmo por falta de orientação e de recursos metodológicos. A formação dos/as profissionais ao trabalhar com temáticas (em geral, paradigmáticas) é de grande importância para que não haja interferência de valores individuais nos conteúdos, evitando sempre a "propagação" de preconceitos ou ideias inadequadas. Além disso, o fato de nunca terem trabalhado temáticas relacionadas à gênero e sexualidade já é um fator preocupante, dado que essas questões perpassam, direta ou indiretamente, todos os conteúdos e saberes no campo da práticas corporais e, não estar atento e/ou bem formado para o trato com essas questões pode contribuir para uma atuação pouco consciente e, em muitos casos, reprodutora de estereótipos, preconceitos e diferenciações baseados no senso comum e na manutenção de paradigmas excludentes.

Holanda et al. (2010) complementa dizendo que os profissionais de educação física cheios de insegurança e despreparados acabam encontrando barreiras para auxiliar as crianças sobre o assunto, pois, quando se discute sobre gênero e sexualidade, é necessário que o/a educador/a possua atributos, como: sensibilidade, habilidade, aprendizado e atualização. O/a profissional deve estar preparado para lidar com valores, tabus e preconceitos de modo consciente e responsável do seu papel social. Consequentemente, a falta de um diálogo acerca das identidades de gênero e diversidade sexual traz consigo o silenciamento, invisibilidade e exclusão das pessoas que assumem identidades fora dos binarismos e/ou da matriz heterossexual, principalmente no ambiente escolar, fixando valores heteronormativos (JUNQUEIRA, 2013).

A pessoa construída como "diferente" passa então a ser policiada e, não raro, proibida de acessar espaços comuns ao grupo. A tolerância é instaurada, caso sua presença seja "necessária", motivada por algum interesse maior, como por exemplo, no caso das práticas esportivas, completar o número de jogadores de um time para que o jogo ocorra, conforme apontado por Dornelles (2013).

Propiciar nas aulas variadas possibilidades de relacionamento, nas quais a diversidade não seja vista ou imposta como um 'problema' depende de ações pedagógicas atentas a essa dimensão das relações humanas, ou seja, o/a professor/a é responsável por atribuir vivências que valorizem a relação harmoniosa dos/as alunos/as com a diversidade.

Outra pergunta visava refletir sobre a concepção dos/as docentes acerca das práticas esportivas diferenciadas quanto ao gênero e, nesse quesito, a maioria dos/as entrevistados/as responderam não considerar que deva haver atividades específicas. No entanto, entre as 
justificativas, algumas falas contribuem para o debate, explicitando diferenças ainda presentes no imaginário social:

Não. Porém o futebol costuma ser bem mais popular entre os meninos (Marcia, 29).

As mídias influenciam as famílias mostrando imagens de alguns esportes sempre relacionando a homens, exemplo é o futebol, passa 3 vezes na semana e tem programas exclusivos para discussão, e falam muito pouco do futebol feminino, as federações também poderiam valorizar mais os campeonatos brasileiros femininos, pois é pouco visto, e muitas questões como salários e prêmios que para as mulheres geralmente é muito abaixo do masculino. Todas essas questões influenciam em nossas aulas, porém não tiro nossa responsabilidade de mostrar e incentivar a participação das mulheres e mostrar seu espaço nas modalidades esportivas. Tenho muitas alunas que são muito habilidosas em basquete, handebol e vôlei, mas não gostam do futsal, e têm habilidades para serem ótimas jogadoras (Marcos, 28).

Especialmente entre as respostas afirmativas, Catarina afirma que a dança é diferenciada, justificando que "[...] tem muitos pais que ainda acham que a dança é só para as meninas" (Catarina, 39).

Sobre a percepção dos docentes quanto ao pensamento dos/as alunos/as em relação as práticas diferenciadas, apenas quatro afirmam que os/as alunos/as não diferenciam atividades quanto ao gênero. Entre as constatações quanto à diferenciação, afirmam:

Como dito, a atualidade também depende das experiências anteriores, seja escolar ou familiar. A família neste caso está intrinsicamente ligada a formação do pensamento do aluno desde casa no que ele deve brincar. Um exemplo é que menino joga bola e menina brinca de boneca ou fica com os bambolês e corda na educação física, infelizmente é a realidade que tanto tentamos mudar (José, 22).

Existem alunos que enxergam desta forma e tem preferência de realizar determinadas atividades esportivas. Ex.: meninos jogam futebol e meninas pulam corda. Mas em minhas aulas todos participam de tudo (Débora, 26).

Nas series finais do Ensino Fundamental e Ensino Médio esse pensamento é mais comum entre eles. As meninas começam a ser menos participativas (Marcia, 29).

Vejo a dança como um tabu difícil de quebrar pela cultura. Difícil meninos entenderem que todos podem fazer dança por exemplo e que isso não tem nada a ver com ser menina ou menino (Talita, 37).

Ainda há, no cenário atual, propagação de tabus, padrões ou preconceitos. Pode-se citar, facilmente, alguns exemplos nas quais esportes são rodeados de tabus: a hegemonia masculina no futebol e lutas, a "hegemonia" feminina no vôlei e danças. Talvez, este seja um fator 'naturalizado' para a grande maioria dos que responderam que nunca trabalharam esse conteúdo, pois se não conseguem vislumbrar a problemática, dificilmente irão fazer reflexões a partir de tal conteúdo. Atestando que a educação física é uma área transpassada por regulações de gênero e construção de modelos hegemônicos de masculinidade e feminilidade, José Devís, Jorge Miguel e Andrew Sparkes (2005) fornecem indícios de que a heterossexualidade compulsória e a homofobia 
acompanham estudantes durante suas experiências nas aulas desse componente curricular, sendo uma pedagogia cultural ${ }^{4}$ que interfere nas vivências nas aulas. Goellner (2010) afirma que o corpo é um construto social baseados nos significados culturais e que, portanto, as experiências desse corpo são significadas também a partir de diferentes pedagogias culturais, algumas delas ainda cerceadoras da liberdade.

A manutenção de formas hegemônicas de conceber masculinidade e feminilidade ainda está presente no cotidiano das aulas de educação física. Tal preconceito foi enraizado entre as gerações e não só no esporte. Um estudo realizado por Nascimento, Nascimento e Oehlschlaeger (2011) apresenta dados que demonstram o número reduzido de homens que praticam danças em Pelotas, RS. Apenas $23,3 \%$ dos praticantes de dança da cidade são homens. Esse dado fica menor se compararmos com a modalidade ballet clássico, que apresenta apenas 20 homens dançando de um total de 403 dançarinas/os.

Quando questionamos acerca da percepção dos/as docentes sobre uma maior o menor participação dos/as alunos/as nas aulas de educação física, algumas respostas explicitam a questão:

Experiências anteriores podem acarretar a este fenômeno bem como a falta de estímulo por parte dos docentes. Meninos não se habituam facilmente com atividades lúdicas, querem apenas o esporte "futebol" (José, 22).

Acho que a atividade física por muito tempo estava relacionada, enraizada ao gênero masculino, esporte igual a masculinidade. Apesar de nas minhas aulas todos participarem, vejo uma PREFERÊNCIA pelas atividades pelos meninos (Talita, 37).

Há uma cultura impregnada principalmente pelo futebol, que é mais praticado pelos meninos, nesse esporte poucas meninas se interessam, a maioria é resistente a prática. Vejo que estamos aos poucos avançando (Marcos, 28).

Ainda nesse sentido, ao serem questionados/as sobre a importância de aulas mistas, todos/as os/as docentes recorrem a aulas mistas com a potencialidade da "[...] construção de valores (cooperação, trabalho em grupo, espírito de equipe) [...]” (José, 22), “[...] conviver em sociedade [...] e respeitar o próximo [...]” (Marcos, 28), tendo o direito de participar, “[...] sem exclusão social (Vanessa, 21). Nesse sentido, afirmam que "[...] não pode haver divisão, temos que mostrar que todos são iguais e tem a mesma condição de realizar a atividade, seja ela qual for" (Debora, 26) e que a aula mista "[...] torna rica a aula [...] justamente [pela] vivência entre a diversidade, o trabalho em conjunto e o respeito mútuo" (Marcia, 29).

Entre os pontos positivos e negativos explicitados quanto à aula mista, alguns professores/as afirmam:

${ }^{4}$ Como um conjunto de saberes e práticas, a(s) pedagogia(s) culturais estão centradas nos sujeitos e na sua formação, nostempos e espaços que o constituem. Portanto, pedagogias culturais compõem as dinâmicas que sustentam aconstrução das subjetividades. 
Positivo: paridade de todos os alunos e mostra para a turma que não existe diferença; em certas atividades a mistura ajuda para "equilibrar" as equipes na hora principalmente da competição. Negativo: Existe a dificuldade de coordenar a turma e fazer com que eles "aceitem" essa mistura (Debora, 26).

Não vejo pontos negativos nas aulas mistas, pois as aulas de Educação Física não são para rendimentos, portanto é o ambiente ideal para trabalho em equipe, respeito ao próximo e outros. Sei que não é fácil, porém acredito ser fundamental uma discussão teórica com os alunos antes de iniciar as práticas (Marcos, 28).

Interessante perceber a resposta de alguns/mas entrevistados quanto à separação em determinadas atividades (você separa meninas e meninos em algumas atividades da Educação Física? Se sim, em quais?). As respostas demonstram que há separação por gênero, com predominância para as aulas mistas. Apenas 6 relatos afirmam não separar em nenhuma atividade. Entre as justificativas:

Sim, as que precisam utilizar força (Marcela, 21).

Sim. Em alguns momentos pela força física que os meninos tem, medo de machucar as meninas (Talita, 37).

Quando se aproxima dos jogos interclasses da instituição, pois no campeonato jogam separados, mas na maior parte do ano letivo trabalho juntos (Marcos, 28).

A exceção em separar meninos e meninas eu uso apenas em algumas atividades de competição pois são grupos fáceis de ser identificado e acaba sendo mais prático e economizando tempo (Marcia, 29).

Infelizmente, percebemos em diferentes estudos a mesma realidade, como exposto em outro estudo realizado com professores de Campinas, na qual verificou-se que algumas questões como competitividade e diferença de força física acabam afastando as meninas das práticas das aulas de educação física (ALTMANN, H; AYOUB, E; AMARAL, S. C. F, 2011).

Ainda há professores/as da educação básica que optam por turmas separadas, embora a literatura aponte para maior valorização de aulas mistas, como evidencia Dornelles (2011, p. 17) por meio de uma das entrevistas realizadas com professores/as: "Eu prefiro trabalhar separado. [...] Porque os meninos, eles já têm um certo adiantamento. Eles já estão fisicamente mais preparados. [...] Os meninos estão soltos na rua há muito tempo. As meninas estão sendo soltas agora”. Esse aspecto acaba por legitimar uma diferenciação que é explicitamente uma marca da cultura, evidenciando como meninos e meninas são diferentemente socializados e, portanto, possuem diferenças em relação à apreensão de certas habilidades no campo da educação física. No entanto, para superar tal diferenciação, explícita pelo docente, o caminho não seria manter essa diferenciação ao longo da escolarização, mas buscar minimizar os efeitos de uma cultura sexista, que ainda diferencia, desde a mais tenra idade, atividades consideradas masculinas e femininas, limitando, em muitos aspectos, a experiência de meninas em práticas corporais e esportivas. 
Nesse seguimento, há responsabilidade na atuação do/a professor/a diante das questões de gênero e sexualidade na educação física. No estudo realizado com os professores de Campinas foram identificadas falhas na formação dos professores, a partir dos relatos deles. Nas falas de alguns, eles/as expuseram a falta de planejamento para atuar no sentido de fomentar a participação das meninas (ALTMANN; AYOUB; AMARAL, 2011).

Menezes et. al. (2010, p. 249) atestam que "há uma separação durante as aulas de Educação Física, feita pelo próprio professor e pelos alunos, onde na maioria das vezes, pelo fato da liderança ser na maioria masculina, os meninos jogam futebol e as meninas fazem outra atividade, ou não fazem nada durante a aula".

Outro estudo identificou dificuldades pedagógicas nas aulas de educação física, tanto na exposição do conteúdo de gênero e sexualidade, quanto na realização de aulas mistas (FARIA, 2001). É impossível falar de participação igualitária entre gêneros e exposição de conteúdos diferenciados nas aulas de Educação Física quando nos deparamos com a falta de vontade ou aperfeiçoamento dos/as professores/as e/ou mesmo a dificuldade na diversificação dos conteúdos.

A diversificação dos conteúdos tem sido uma questão muito discutida na Educação Física. Zabala (1998) afirma que para haver diversificação de conteúdo é necessário explorar os conteúdos em três dimensões: 1) "o que se deve saber?" (dimensão conceitual), "o que se deve saber fazer?" (dimensão procedimental), e "como se deve ser?" (dimensão atitudinal), com a finalidade de alcançar os objetivos educacionais.

Neste sentido, o papel da educação física ultrapassa o ensinar esporte, ginástica, dança, jogos, atividades rítmicas, expressivas e conhecimento sobre o próprio corpo para todos, em seus fundamentos e técnicas (dimensão procedimental), mas inclui os valores subjacentes, ou seja, atitudes que os/as alunos/as devem ter nas e para as atividades corporais (dimensão atitudinal). Finalmente, busca garantir o direito do/a aluno/a de saber o porquê de estar realizando este ou aquele movimento, correlacionando aos conceitos ligados àqueles procedimentos (dimensão conceitual) (ZABALA, 1998).

Por fim, os/as docentes exploraram o que consideram importante para a adesão completa dos/as alunos/as às aulas de Educação Física (gráfico 1): 
Gráfico 1 - o que poderia atrair ou incluir mais alunos/as nas aulas de Educação Física

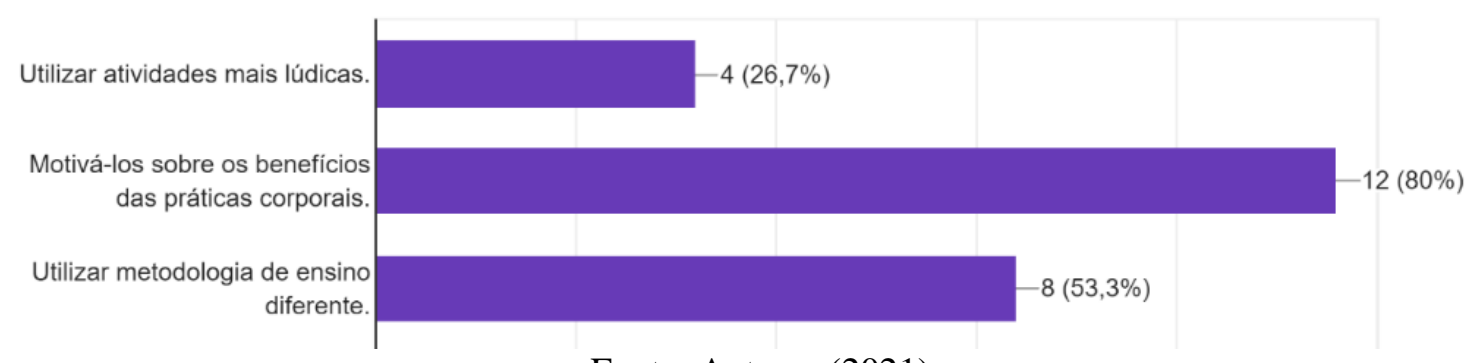

Fonte: Autores (2021)

Pode-se destacar que o fator motivacional foi o mais assinalado pelos pesquisados/as, seguido por fatores metodológicos. No entanto, se observarmos o gráfico 2, verificamos os motivos assinalados pelos/as docentes quanto a evasão e não participação dos/as alunos/as nas aulas.

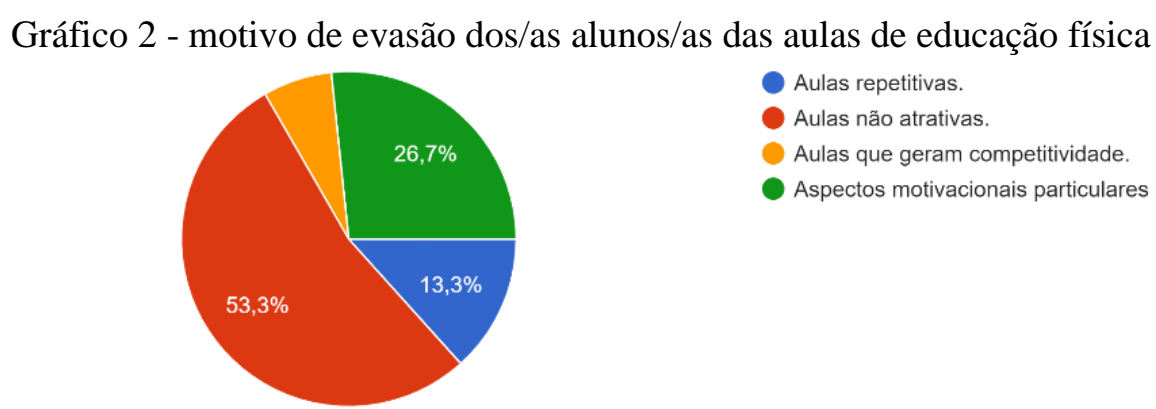

Fonte: Autores (2021).

Entre os motivos assinalados estão as aulas não atrativas com 55,3\% (8 docentes) e/ou repetitivas (13,3\% - 2 docentes), sendo que apenas 4 docentes $(26,7 \%)$ consideram aspectos motivacionais e 1 docente $(6,7 \%)$, aulas competitivas. Assim, há a necessidade de reflexões mais aprofundadas quanto aos aspectos metodológicos e de planejamento, no sentido de buscar reduzir a evasão e o desinteresse pelas aulas de educação física.

\section{CONSIDERAÇÕES FINAIS}

A relação com os dados e a literatura é interessante, mas será que é possível pensar para além do que já está posto? Sugiro nas considerações reconhecer os limites da pesquisa.A educação física é uma disciplina escolar que deve ser problematizada no sentido de questionar que tipo de formação pretende e como a escola constrói mecanismos reguladores para que tal objetivo seja alcançado. Diante disso, o presente estudo traz contribuições para a área de educação física no que diz respeito a igualdade de participação nas aulas e a exposição do conteúdo gênero e sexualidade, 
refletindo sobre o papel da prática docente nesse processo formativo. Apesar de destinar-se a refletir sobre a educação física, vale pontuar que ao se referir às questões de gênero e sexualidade a responsabilidade pelo debate não se restringe à educação física, mas ao debate transdisciplinar.

As análises dos questionários permitiram compreender aspectos importantes acerca da prática docente em educação física e o debate sobre as questões de gênero. Há consenso quanto a um ponto, quando refletimos sobre as questões de gênero na pesquisa: a importância de se trabalhar com turmas mistas. A prática alicerçada na igualdade de participação nas aulas de educação física precisa problematizar concepções estereotipadas do feminino e do masculino, da masculinidade e da feminilidade, presentes no ambiente escolar.

Foi possível verificar a falta de formação para o trabalho que pense sobre gênero e sexualidade nas aulas de educação física. Os/as professores/as demonstram dificuldades para utilizar estratégias visando proporcionar reflexões a respeito de tabus, influência midiática ou até mesmo sobre a temática de gênero e sexualidade. Não foi possível identificar com clareza as barreiras que refletem esta realidade nas falas docentes, no entanto, diversas pesquisas salientam a falta de formação como um empecilho ao debate.

Entre as limitações da pesquisa, destacamos a baixa participação de docentes, considerandose o quadro total de docentes da rede municipal de Dourados (em média, 80 a 100 docentes efetivos vinculados à rede, desconsiderando-se nesse número os contratos temporários firmados para suprir necessidades pontuais). Entendemos que esse baixo retorno se deve a pelo menos dois fatores: 1 . A pandemia e o excesso de demandas docentes em ambientes online; 2 . A temática da pesquisa que acaba por problematizar aspectos pouco debatidos e, em muitos casos, ignorados e/ou difíceis de serem debatidos por grande parte dos/as docentes que atuam na Educação Física, percebidos em momentos de formação continuada em que debates a partir dessa temática surgiram. Um aspecto importante a ser ressaltado também se refere à participação majoritária de mulheres que também se mostraram mais abertas e afetadas pela temática em voga. É possível que a temática não preocupe igualmente homens e mulheres, sobretudo por ainda estarmos inseridos em lógicas societárias que (des)legitimam as desigualdades de gênero em diferentes espaços e, também, na educação física. Homens e mulheres percebem diferentemente essas questões e o modo como elas interferem em suas vivências e, portanto, pode representar um empecilho para refletirem sobre suas próprias práticas docentes.

A realidade construída, até então, tem desafiado os/as profissionais de educação física, porque abalam as zonas de conforto. É necessário que os/as professores/as busquem aperfeiçoamento, pois o ambiente escolar proporciona aos mesmos vários desafios. E este estudo trouxe algumas constatações, no sentido de ressaltar que a educação física, por meio de seus 
conteúdos, pode fazer diferença. Para isso é preciso voltar-se a aspectos fundamentais: inovação metodológica; respaldo científico; buscar suprir as carências da formação acadêmica; procurar se especializar e buscar formação continuada; diversificar os conteúdos e trazê-los para a realidade social dos/as alunos/as. Essas são algumas possibilidades.

\section{REFERÊNCIAS}

ABREU, Meriane Conceição Paiva, WANDEKOKEN, Wagner Magalhães. Amarelinha Versus Futebol, Por que não ambas? Um Estudo das Relações de Gênero no Projeto Esporte e Lazer da Cidade. 2005. Monografia (Licenciatura em Educação Física) - Departamento de Educação Física, Universidade Federal do Pará, Castanhal, 2005.

ALTMANN, Helena; AYOUB, Eliana; FRANCO, S. C. Gênero na prática docente em educação física: "meninas não gostam de suar, meninos são habilidosos ao jogar"? Revista de Estudos Feministas, Florianópolis, v. 12, n. 02, p.491-501, maio/ago. 2011. Disponível em: https://www.scielo.br/j/ref/a/p8cj4Xpntfdhx4ncS8ZLJwj/abstract/?lang=pt. Acesso em: 02 dez. 2020.

BRASIL. Parâmetros Curriculares Nacionais: terceiro e quarto ciclos: Educação Física/ Secretaria de Ensino Fundamental. Brasília: MEC/ SEF, 1998. Disponível em:

http://portal.mec.gov.br/seb/arquivos/pdf/introducao.pdf. Acesso em: 20 nov. 2020.

BRASIL. Decreto-Lei n ${ }^{\circ}$ 3.199, de 14 de abril de 1941. Estabelece as bases de organização dos desportos em todo o país. Decreto-Lei No 3.199, de 14 de Abril de 1941.: Legislação federal.. Rio de Janeiro, RJ, 14 abr. 1941. Disponível em: https://www.planalto.gov.br/ccivil_03/decreto-lei/1937-1946/del3199.htm. Acesso em: 06 jun. 2021.

BUTLER, Judith. Problemas de gênero: feminismo e subversão das identidades. Rio de Janeiro: civilização brasileira, 2003.

CORSINO, Luciano Nascimento; AUAD, Daniela. Questões de gênero na Educação Física escolar: o professor diante das relações de gênero na Educação Física Escolar. São Paulo: Cortez, 2012. 111 p.

DARIDO, Suraya. C.; RANGEL. Irene. C. A. Educação física na escola: questões e reflexões. Rio de Janeiro: Guanabara Koogan, 2005.

DEVÍS DEVÍS, José; MIGUEL, Jorge F.; SPARKES, Andrew C. Qué permanece oculto del currículum oculto? Las identidades de género y de sexualidad em la Educación Física. Revista Iberoamericana de Educación. n. 39, p. 73-90, 2005. Disponível em: https://rieoei.org/historico/documentos/rie39a03.pdf. Acesso em: 20 nov. 2020.

DORNELLES, Priscila G. Marcas de gênero na educação física escolar: a separação de meninos e meninas em foco. Motrivivência, Florianópolis, v.13, n. 37, p. 12-29, 2011. Disponível em: https://periodicos.ufsc.br/index.php/motrivivencia/article/view/2175-8042.2011v23n37p12. Acesso em: 06 jun. 2021.

DORNELLES, Priscila G. A (hetero)normalização dos corpos em práticas pedagógicas da educação física escolar. 2013. Tese (Doutorado em Educação) - Programa de Pós-Graduação em Educação, Faculdade de Educação, Universidade Federal do Rio Grande do Sul, Porto Alegre, 2013. Disponível em: https://www.lume.ufrgs.br/handle/10183/78768\#: :text=A\%20investiga\%C3\%A7\%C3\%A3o\%20realizada\% 20permite\%20dizer,Educa\%C3\%A7\%C3\%A3o\%20F\%C3\%ADsica\%20escolar.\%20.... Acesso em: 08 mar. 2021. 
FARIA, Eliene L. O esporte na cultura escolar: usos e significados. 2001. Dissertação (Mestrado em Educação) - Programa de Pós-Graduação em Educação, Faculdade de Educação, Universidade Federal de Minas Gerais, Belo Horizonte, 2001.

FOUCAULT, Michel. História da Sexualidade I: A vontade de saber. Rio de Janeiro: Graal, 1993.

FREIRE, Paulo. Pedagogia da autonomia: saberes necessários à prática educativa. São Paulo: paz e terra, 2011.

FREITAS, Milena de Bem Zavanella; SOUZA JUNIOR, Osmar Moreira de. Gênero, sexualidade e educação física: formação e prática docente. Motricidades, v.4, n.3, p.217-230, set./dez.2020. Disponível em: https://www.researchgate.net/publication/347733641_Genero_sexualidade_e_educacao_fisica_formacao_e_ pratica docente. Acesso em: 03 mai. 2021.

GHIRALDELLI Jr. Paulo. Educação Física Progressista: A pedagogia crítico-social dos conteúdos e a Educação Física Brasileira. 9 ed. São Paulo: Edições Loyola, 2004.

GOELLNER, Silvana Vilodre. A produção cultural do corpo. In: LOURO, Guacira Lopes; NECKEL, Jane F.; GOELLNER, Silvana V. Corpo, gênero e sexualidade: um debate contemporâneo na educação.

Petrópolis: Vozes, 2003. p. 28-40.

GOELLNER, Silvana Vilodre. A educação dos corpos, dos gêneros e das sexualidades e o reconhecimento da diversidade. Revista Caderno de formação RBCE, p.71-83, mar. 2010. Disponível em: http://revista.cbce.org.br/index.php/cadernos/article/view/984. Acesso em: 12 set. 2020.

GEERTZ, Cliford. A Interpretação das Culturas. Rio de Janeiro: Guanabara Koogan S.A., 1989.

HOLANDA, Marília L. et al. O papel do professor na educação sexual de adolescentes. Cogitare Enfermagem, v. 15, n. 4, p. 702-708, 2010. Disponível em:

https://revistas.ufpr.br/cogitare/article/view/20371. Acesso em: 05 mai. 2021.

JACO, Juliana F. Educação física escolar e gênero: Diferentes maneiras de participar das aulas. 2012. Dissertação (Mestrado em Educação Física) - Programa de Pós-Graduação em Educação Física, Faculdade de Educação Física, Universidade Estadual de Campinas, Campinas, 2012. Disponível em: http://repositorio.unicamp.br/jspui/handle/REPOSIP/275040. Acesso em: 20 fev. 2020.

JESUS, Mauro L; DEVIDE, Fabiano P. Educação Física Escolar, Co-educação e Gênero: mapeando representações discentes. Revista Movimento. Porto Alegre, v.12, n.03, p. 123- 140, set./dez. 2006. Disponível em: https://seer.ufrgs.br/Movimento/article/view/2912. Acesso em: 14 mar. 2021.

JUNQUEIRA, Rogério D. "Temos um problema em minha escola: um garoto afeminado demais." Vigilância de gênero, heteronormatividade e heterossexismo no cotidiano escolar: notas sobre a pedagogia do armário. In: MAIO, Eliane. R.; CORREA, Chrishna. M. A. (Orgs.). Gênero direitos e diversidade sexual: Trajetórias escolares. Maringá: UEM, 2013.

LOURO, Guacira. L. Gênero, sexualidade e educação: Uma perspectiva pós-estruturalista. Petrópolis: Vozes, 1997.

LOURO, Guacira L. Currículo, gênero e sexualidade. Porto: Porto, 2000.

LOVISI, Ayra; PROCÓPIO, Luana; MOURÃO, Ludmila. Saberes docentes e atravessamentos de gênero na educação física escolar. Anais eletrônicos, Seminário Internacional Fazendo Gênero 10,

Anais...,Florianópolis, 2013. Disponível

em:http://www.fg2013.wwc2017.eventos.dype.com.br/resources/anais/20/1373321131_ARQUIVO_Fazendo generocorrigido.pdf. Acesso em: 10 jan. 2020. 
MAIA, Ana Claudia B. et al. Educação sexual na escola a partir da psicologia histórico-cultural. Psicologia em estudo, Maringá, v. 17, n. 1, p. 151-156, jan./mar. 2012. Disponível em:

https://www.scielo.br/j/pe/a/rQ3DZwPrv5mcTgpYVTrWjTq/?lang=pt. Acesso em: 30 mar. 2021.

MENEZES, Isabela S; SANTOS, Marcela G; SÁ, Kátia R; BORGES, Liliana. Relação entre meninos e meninas nas aulas de Educação Física: um estudo de caso. Coleção Pesquisa em Educação Física, Belo Horizonte, v.9, n.1, p.245-250, 2010. Disponível em:

https://fontouraeditora.com.br/periodico/upload/artigo/577_1502738950.pdf. Acesso em: 20 out. 2020.

NASCIMENTO, Diego E; NASCIMENTO, Flávia M; OEHLSCHLAEGER, Maria H. K. O homem na dança: um estudo comparativo do sexo masculino nos meios formais e não formais de ensino na cidade de Pelotas, RS. EFdeportes -Revista Digital, Buenos Aires, v.16, n.155, abr./ 2011. Disponível em:

https://www.efdeportes.com/efd155/o-homem-na-danca-um-estudo-comparativo.htm. Acesso em: 24 mar. 2021.

PEREIRA, Erik G.B; FERNANDES, José. A construção das masculinidades: os discursos e as imagens na educação física infantil. Rev Inter Science Place, v.2, n.8, p.1-7, 2009.

SANTOS, Éderson C. dos. Um jeito masculino de dançar: pensando a produção das masculinidades de dançarinos de hip hop. 2009. Dissertação (Mestrado em Educação) -Programa de Pós-graduação em Educação, Universidade Federal do Rio Grande do Sul, Porto Alegre, 2009. Disponível em:

https://lume.ufrgs.br/handle/10183/21854. Acesso em: 20 nov. 2020.

SARAIVA, Maria do C. Por que investigar as questões de gênero no âmbito da Educação Física, Esporte e Lazer? Motrivivência, v.13, n. 19, p. 79-85, 2002. Disponível em:

https://periodicos.ufsc.br/index.php/motrivivencia/article/view/958. Acesso em: 15 out. 2020.

SAYÃO, Rosely. Saber o sexo: os problemas da informação sexual e o papel da escola. In: AQUINO, Júlio G. (org.) Sexualidade na escola: alternativas teóricas e práticas. São Paulo: Summus,1997.

SOARES, Carmen L. Educação Física escolar: conhecimento e especificidade. Revista Paulista de Educação Física, São Paulo, v.2, p.6-12, 1996. Disponível em: https://www.revistas.usp.br/rpef/article/view/139637. Acesso em: 13 dez. 2020.

SOARES, Zilene P.; MONTEIRO, Simone S. Formação de professores/as em gênero e sexualidade: possibilidades e desafios. Educar em Revista, Curitiba, Brasil, v. 35, n. 73, p. 287-305, jan./fev. 2019. Disponível em: https://www.scielo.br/j/er/a/KMSmJfk43rKWcRNHWHfWsfC/?lang=pt. Acesso em: 13 dez. 2020.

VASCONSELOS, Camila Midori Takemoto; FERREIRA, Lilian Aparecida. A formação de futur@s professor@s de educação básica: reflexões sobre gênero e sexualidade. Educação em Revista, Belo Horizonte, v.36, p.1-17, 2020. Disponível em:

https://www.scielo.br/j/edur/a/nhzvnNmtMP7L6wYRcC4Dh8B/?lang=pt. Acesso em: 12 mar. 2021.

ZABALA, Antonio. A prática educativa: como ensinar. Porto Alegre: Artmed, 1998. 


\section{NOTAS DE AUTOR}

AGRADECIMENTOS - Não se aplica.

CONTRIBUIÇÃO DE AUTORIA - Não se aplica.

FINANCIAMENTO - Não se aplica.

CONSENTIMENTO DE USO DE IMAGEM - Não se aplica.

\section{APROVAÇÃO DE COMITÊ DE ÉTICA EM PESQUISA}

CAAE: 23446919.1.0000.5160. Pesquisa de iniciação científica vinculada ao Projeto de Pesquisa docente: CORPO(S), CULTURA(S) E IDENTIDADE(S): A EDUCAÇÃO FÍSICA NO BOJO DAS DISCUSSÕES DE GÊNERO, SEXUALIDADE E SUAS INTERSECCIONALIDADES.

CONFLITO DE INTERESSES - Não há conflito de interesses.

\section{LICENÇA DE USO}

Os autores cedem à Motrivivência- ISSN 2175-8042 os direitos exclusivos de primeira publicação, com o trabalho simultaneamente licenciado sob a Licença Creative Commons Attribution NonComercial ShareAlike (CC BY-NC SA) 4.0 International. Esta licença permite que terceiros remixem, adaptem e criem a partir do trabalho publicado, desde que para fins não comerciais, atribuindo o devido crédito de autoria e publicação inicial neste periódico desde que adotem a mesma licença, compartilhar igual. Os autores têm autorização para assumir contratos adicionais separadamente, para distribuição não exclusiva da versão do trabalho publicada neste periódico (ex.: publicar em repositório institucional, em site pessoal, publicar uma tradução, ou como capítulo de livro), com reconhecimento de autoria e publicação inicial neste periódico, desde que para fins não comerciais e compartilhar com a mesma licença.

\section{PUBLISHER}

Universidade Federal de Santa Catarina. Programa de Pós-Graduação em Educação Física. LaboMídia - Laboratório e Observatório da Mídia Esportiva. Publicado no Portal de Periódicos UFSC. As ideias expressadas neste artigo são de responsabilidade de seus autores, não representando, necessariamente, a opinião dos editores ou da universidade.

\section{EDITORES}

Mauricio Roberto da Silva, Giovani De Lorenzi Pires, Rogério Santos Pereira.

\section{EDITOR DE SEÇÃO}

Bianca Poffo

\section{REVISÃO DO MANUSCRITO E METADADOS}

Juliana Rosario; Keli Barreto Santos.

\section{HISTÓRICO}

Recebido em: 20 de setembro de 2021.

Aprovado em: 08 de dezembro de 2021. 